\title{
Mathematics in Society - a Power for Change
}

\author{
AISLING E. MCCLUSKEY
}

\section{INTRODUCTION}

... I also have this sense in my bones that service is going to reemerge with greater vitality than we have seen it in the last 100 years, simply because the university must be engaged if it hopes to survive. The social imperative for service has become so urgent that the university cannot afford to ignore it [Boyer, 1995].

A movement, known variously as civic engagement, community based learning and service learning among others, is quietly and effectively taking root in Ireland (www . campusengage.ie). This note derives from my initial uncertain understanding of, and belief in, it as a concept, all the while accompanied by a nagging sense of its potential value and relevance to the mathematical community as a whole. Accordingly, I offer an outline of the origin and spirit of the movement, and some preliminary thoughts on how and where mathematics might fit within it. Notably, this exploration has assured me that mathematics at third level has a growing participation in civic engagement, but it is as a discrete, often uncelebrated, enterprise, on the level of individuals rather than a stronger, vibrant national drive. I believe that this movement provides a structure in which to harness and celebrate individual effort and excellence into collective empowerment and impact.

\section{BACKGROUND}

The origins of civic engagement arose naturally in the U.S. where institutions of higher education historically were founded with clear commitment to associated public purposes and to the common good. 
Such purposes included the training of the next generation of the nation's leaders by the creation of colonial colleges, serving the nation's agricultural and technical needs by the establishment of public land grant colleges in the late 1800s, and more recently, in the 1960s, addressing the need for a more diverse work force with the establishment of two-year community and technical colleges [Hollander, 2005]. With an unequivocal mission to inspire active citizenship in its students, it was inevitable that a decline in delivering on such public aspiration would first become highlighted in the U.S. in an authoritative manner.

Campus Compact (www.compact.org) was the U.S. response to an increasing concern about the demonstrably diminishing impact of higher education on general social capital, and to awareness of the support institutions could potentially offer local communities in a meaningful way. Established in 1985, it has grown to a coalition of more than 1,100 institutions of higher education across the U.S. and elsewhere, and includes D.I.T. and NUI Galway as members. Its initial focus was to promote more active involvement in and partnership with communities but within a short time it became apparent that a broader scope and approach was called for. Thus Campus Compact works to build civic engagement into campus and academic life by influencing education policy, providing training and technical assistance, developing extensive print and online resources, creating opportunities for ongoing discourse, and making available grant opportunities (www.compact.org).

Ernest Boyer (1928-1995) is lauded as the individual most responsible for challenging academia to rethink its relationship to the public good. He took the bold step of suggesting that it was time to reassess the academy's priorities and in particular he highlighted the need for a deeper appreciation of the value of teaching and service as scholarship. Indeed, his remarks in a 1995 address (above) were prophetic. He further expressed his concern that the university was increasingly viewed as a private benefit, not a public good. Certainly in the Irish context, the great diversification that has happened in higher education over the past twenty years mitigates against such a charge. And yet, with universities warping and yielding to the increasing demands of government in the name of public good (for which, read variously knowledge/smart economy, globalisation, skills, research, world class standard, entrepreneurialism, enterprise), there is a certain irony and a certain inevitability in where we are today in 
the context of Irish higher education. Pursuing objectives ostensibly in the name of public good has led us on a charge for immediacy, relevance, focus and of course funding - at some cost to us. Significantly, I believe this cost includes that of the roundedness of education, which brings with it a holistic development of person, and also the marginalisation of so-called basic research. I believe also that this cost has paradoxically brought about the will to embrace the concept of civic engagement - and an opportunity to address the nation's need for mathematical strength. Boyer's comment resonates:

Unless we recast the university as a publicly engaged institution, I think our future is at stake.

Some 15 years on, one realizes just how far-sighted his vision was.

On foot of it, a call was made in early 1995 for the development of a series of volumes on service learning in individual academic areas. The American Association for Higher Education was tasked with this, and the project reached completion in 2000. The series explored both theoretical/contextual and practical issues involved in linking academically rigorous course work with projects involving the public good [13]. Significantly, the Mathematical Association of America stewarded the volume for the mathematical sciences.

So what is civic engagement as it applies to academia, and particularly as it might or should apply to mathematics?

\section{THE MATHEMATICIAN'S STOCK-IN-TRADE: DEFINITIONS AND LITERATURE}

As is imperative with a notion that seeks agency and authority, civic engagement is supported by an ample body of academic literature that explores a broad spectrum of critical issues. At the core of these lie the essence, the appropriateness and the viability of such engagement. But what exactly is civic engagement, particularly as it applies to the academy? Boland and McIlrath [2] capture succinctly the growing uncertainty one gleans from literature review as terminology such as service learning, community based learning, civic engagement is used interchangeably. Thus in [6], Hadlock describes civic engagement as a set of activities that have two characteristics:

(1) they enhance either the delivery or the impact of curricular material, usually, but not always, within the context of a specific course, and 
(2) they take place within a service framework where additional experience with civic engagement or social contribution will be obtained.

Boland and McIrath remark that the term service learning originates in the U.S. where it has positive connotations and that it has been adopted in Ireland to describe a variety of diverse practices. Further, they note the level of discomfort felt by Irish academics concerning the use of the word service in this context. Such is the scale of deterrent wrought by the existence of a broad variety of terms for similar activities that these authors advocate the suspension of any attempt at definition or labelling and propose the use of the term pedagogies for civic engagement (PfCE) as a working label. Indeed terms such as community, citizenship and engagement are contested in both academic literature and in public debate so the need for some degree of clarity or at least agreement on meaning is surely desirable.

\section{THE SCHOLARSHIP OF ENGAGEMENT}

Engagement is a concept much debated in contemporary higher education. On the one hand, it refers to the level of personal commitment given by a student to his/her study and it is the engine that drives an active and enjoyable learning experience. Not surprisingly, it is an issue of great concern to mathematics educators in higher education. In the context of civic engagement, it refers to a new partnership between the academy and civil society [13]. Zlotowski argues convincingly that engagement must not only characterise both student effort and institutional posture, it must also-in both its forms - play a constituent part in the way in which students learn. In this regard, I believe that in and of itself, the learning of mathematics is a pressing civic issue. What other subject ignites such a range of emotion in the general public? There is no doubt that the learning of mathematics at all levels is and should be under the microscope and that the notion of civic engagement elevates efforts to achieve that end, namely effective teaching, to that of scholarship in its own right. Indeed, Zlotkowski claims that it was Boyer whose unpacking of the concept of scholarship promoted the idea that teaching itself could be a form of scholarship. Some of those who champion civic engagement argue along the following lines:

The method people naturally employ to acquire knowledge is largely unsupported by traditional classroom 
practice. The human mind is better equipped to gather information about the world by operating within it than by reading about it, hearing lectures on it, or studying abstract models of it ([1]).

Where mathematics is concerned, this is a dangerous oversimplification. The human mind will not develop advanced mathematical thinking, for example, by being at large in the world. Such thinking is nurtured in a mathematically rich environment, indeed in a mathematical world. Such a view undermines the complexity that underpins the high-level cognitive growth characteristic of advanced mathematics. Further, this point ushers in the oft-cited value of the 'real world', particularly as it applies to mathematics. As mathematicians, we are abundantly aware that mathematics lives in the real world from elementary to, literally, rocket science and examples abound in text books to illustrate this. Yet a common and limiting interpretation of service learning (or civic engagement) for mathematics is that it is about learning mathematics 'for the real world' - which all the while suggests subliminally that practical everyday mathematics takes precedence over curiosity, exploration and discovery. These last three are vital ingredients for the welfare of mathematical thinking and they demand independent thinking, or reflection. Reflection is the mainstay of civic engagement programmes and it is essential for learning mathematics. This common element unites two, perhaps unlikely, partners. It is clear that I have made no argument concerning the civic aspect of learning mathematics, other than asserting that such learning impacts for better or worse every citizen of this country. Rather, my argument is that if we, as mathematics educators at all levels, can improve on the learning of mathematics by, amongst other things, adopting classroom practices that better engage and promote curiosity and creativity, then we are surely contributing to society already. Abbot and Ryan rightly allude to such a need above.

\section{Challenge and Opportunity}

Certainly, many individuals in Ireland have long since subscribed to this and contribute significantly but I believe that a fusion of energy, of ideas and of talent across higher, post-primary and primary education could create a formidable force. Zlotowski describes the MAA-published text [6] as an important resource in encouraging 
and facilitating a greater awareness of possibilities and opportunities that may exist so that academically rigorous, discipline-specific civic engagement becomes accepted as an important part of what mathematicians do and what mathematics departments offer. He continues in his quest to persuade mathematicians of the value of civic engagement for their subject by describing the degrees of reflection that can ensue. The first level, and the one for which mathematicians yearn, has already been described above. He proceeds:

On a second level, service-learning reflection asks the learner to become more aware of what he/she brings to the learning process: values, assumptions, biases many of which are unexamined and potentially problematic.

He refers to differences that students may experience in their interactions with others in terms of educational level, mathematical attitudes and aptitudes, ethnic/racial traditions, or socio-economic circumstances .

To leave these aspects unexplored would be to miss a vital educational opportunity, for they invariably stir up thoughts and feelings highly deserving of reflection and discussion.

This puts us squarely in the realm of Mathematics Education and certainly allows for a further source of valuable data for that field. He argues that a third level of reflection, beyond mathematical competence and heightened awareness, occurs with experiencing the nature of the 'real world' from both an adult and a mathematical perspective. Undoubtedly we have moved far from the remit of an academic mathematician with such reflection - and yet there is surely recognition that Irish society is in urgent need of a mathematics 'fix'. Students involved in civic engagement projects in mathematics may develop a keener sense of how and where problems pertaining to mathematics at least derive - and may be able to contribute effectively to improvement by their civic experience. Informed opinions offer a much better steer towards improvement than rash judgement, and in public debate on pressing issues their voices may resonate. Possible associated civic engagement projects fall naturally and unsurprisingly into three categories: education, mathematical modelling and statistics - and Hadlock ventures that 
there may be other untapped possibilities [7]. The off-the-shelf Undergraduate Ambassadors Scheme (UAS, www.uas.co.uk) is but one highly successful civic engagement venture founded by Simon Singh and Hugh Mason (both with illustrious backgrounds in science promotion) and adopted as credit-bearing modules by some Irish universities in mathematics in the past few years. One thing is clear: the resources required to implement civic engagement projects in the fullest sense particularly for mathematics are great. The risk of 'loose cannons' at large with community partners ostensibly to contribute mathematical know-how is also very real. Yet the potential benefits to the student alone are considerable. Zlotkowski and other proponents attest to an enhanced learning experience due to

(1) motivation from seeing curricular material in action

(2) higher student energy level due to commitment and promise of delivery to community partner

(3) motivation due to higher stakes exposure

(4) greater potential for meaningful reflection

(5) greater desire and need for mastery of one's subject when perceived as a service provider.

I am convinced of an opportunity under the banner of civic engagement to unite individual effort and achievement towards greater mathematical good. Perhaps the last word is best left with Boyer's rallying call:

I am convinced that. . the academy must become a more vigorous partner in the search for answers to our most pressing social, civic, economic and moral problems... At one level, the scholarship of engagement means connecting the rich resources of the university to our children, to our schools, to our teachers and to our cities... But at a deeper level, I have this growing conviction that what's needed is not just more programmes, but a larger purpose, a larger sense of mission, a larger clarity of direction. . Increasingly, I'm convinced that ultimately, the scholarship of engagement also means creating a special climate in which the academic and civic cultures communicate more continuously and more creatively within each other. . enriching the quality of life for all of us. 


\section{REFERENCES}

[1] Abbot, J. and Ryan, T. (1999) 'Learning To Go With the Grain of the Brain', 21st Century Learning Initiative [website] http://www.21learn.org/publ/edcanada.html

[2] Boland, J.A. and McIlrath, L. 2007. 'The Process of Localising Pedagogies for Civic Engagement in Ireland: The Significance of Conceptions, Culture and Context', Higher Education and Civic Engagement: International Perspectives: $83-99$.

[3] Boyer, Ernest L. 1996. 'From Scholarship Reconsidered to Scholarship Assessed', Quest, 48:2, 129-139.

[4] Boyer, Ernest L. 1996. 'The Scholarship of Engagement', Journal of Public Service and Outreach 1:1, 19-20.

[5] Campus Compact, www. compact.org

[6] Hadlock, C. 2005. 'Introduction and Overview', Mathematics in service to the community: concepts and models of service-learning in the Mathematical Sciences, Mathematical Association of America (MAA): 2.

[7] Hadlock, C. 2005. 'Untapped Possibilities?', Mathematics in service to the community: concepts and models of service-learning in the Mathematical Sciences: 237-245.

[8] Hollander, E. 2005. 'Foreword', Higher Education and Civic Engagement: International Perspectives.

[9] Kronman, A.: 2007. 'Education's End: Why our Colleges and Universities Have Given Up on the Meaning of Life', Yale University Press.

[10] Undergraduate Ambassadors Scheme, www.uas.ac.uk

[11] Whitehead, A.N. 1967. 'The Aims of Education and Other Essays', New York: Free Press (first published by MacMillan in 1929)

[12] Zemsky, R. (2003), 'Have We Lost the 'Public' in Higher Education?', The Chronicle of Higher Education, 49:38, B7.

[13] Zlotkowski, E. 2005. 'The Case for Service Learning', Engagement: International Perspectives: Mathematics in service to the community: concepts and models of service-learning in the Mathematical Sciences: 37-52

Aisling E. McCluskey,

Department of Mathematics,

National University of Ireland,

Galway, Ireland

aisling.mccluskey@nuigalway.ie

Received on 15 November 2010. 